\title{
PV-PCM integration in glazed building. Co-simulation and genetic optimization study
}

\author{
Elarga, Hagar; Dal Monte, Andrea; Andersen, Rune Korsholm; Benini, Ernesto
}

Published in:

Building and Environment

Link to article, DOI:

10.1016/j.buildenv.2017.09.029

Publication date:

2017

Document Version

Peer reviewed version

Link back to DTU Orbit

Citation $(A P A)$ :

Elarga, H., Dal Monte, A., Andersen, R. K., \& Benini, E. (2017). PV-PCM integration in glazed building. Cosimulation and genetic optimization study. Building and Environment, 126, 161-175. https://doi.org/10.1016/j.buildenv.2017.09.029

\section{General rights}

Copyright and moral rights for the publications made accessible in the public portal are retained by the authors and/or other copyright owners and it is a condition of accessing publications that users recognise and abide by the legal requirements associated with these rights.

- Users may download and print one copy of any publication from the public portal for the purpose of private study or research.

- You may not further distribute the material or use it for any profit-making activity or commercial gain

- You may freely distribute the URL identifying the publication in the public portal 


\title{
PV-PCM Integration in Glazed Building. Co-Simulation and Genetic Optimization Study
}

\author{
Hagar Elarga ${ }^{1 *}$, Andrea Dal Monte ${ }^{2}$, Rune Korsholm Andersen ${ }^{1}$, Ernesto Benini ${ }^{2}$ \\ 1 International Centre for Indoor Environment and Energy ICIEE,Department of Civil Engineering, \\ Technical University of Denmark Kgs. Lyngby, 2800,Denmark \\ 2 Department of Industrial Engineering, University of Padua, Via Venezia 1, I-35131 Padua, Italy
}

\begin{abstract}
The study describes a multi-objective optimization algorithm for an innovative integration of forced ventilated PV-PCM modules in glazed façade buildings: the aim is to identify and optimize the parameters that most affect thermal and energy performances. 1-D model, finite difference method FDM, thermal resistances technique and enthalpy method were applied to describe different façade solutions and transient thermal performance of PCM. The coupling between the PV-PCM façade code implemented in MATLAB and the TRNSYS software was developed to estimate the dynamic thermal energy profiles. An exploratory step has also been considered prior to the optimization algorithm: it evaluates the energy profiles before and after the application of PCM to PV module integrated in glazed building. The optimization analysis investigate parameters such as ventilation flow rates and time schedule to obtain the best combination suiting the PCM performance and external-internal loads. A group of solution were identified on the Pareto front. Savings in thermal loads for the best individual reached $26.4 \%$ while the best in temperature increment in operating temperatures was recorded as $6.8 \%$ comparing to the design set temperature.
\end{abstract}

Keywords: PV-PCM integrated façade, Genetic Algorithm, Optimization, TRNSYS, Thermal Numerical Simulation

\footnotetext{
${ }^{*}$ Corresponding author: Hagar Elarga

Email address: Hagel@byg.dtu.dk (Hagar Elarga $\left.{ }^{1}\right)$
} 


\section{Introduction}

\subsection{Background - PCM integration to $P V$ and building sector}

Although the building sector represents more than $40 \%$ of the total energy consumption in Europe (El-Sawi et al. [1]), it includes a wide range of possible solutions concerning innovative 5 energetic technologies. One of these solutions is integrating of phase changing materials (PCM) in the building components([2], [3], 4, [5]). Nghana and Tariku [6] have investigated the potential of PCM through numerical and experimental studies. The field experimental study is conducted using twin side-by-side buildings and for the numerical study; EnergyPlus has been used after being benchmarked with the experimental results. It was concluded that PCM are effective in stabilizing the indoor air by reversing the heat flow direction and reducing indoor air and wall temperature fluctuations by $1.4^{\circ} \mathrm{C}$ and $2.7^{\circ} \mathrm{C}$ respectively. Jin et al. [7] have investigated effects of PCM location on the thermal performance of building walls. The experimental results showed that PCM state had great effects on the degree of supercooling and the phase change performance of PCM. Velasco et al. [8] have illustrated the procedure to verify and validate the PCM model in EnergyPlus using a similar approach as dictated by ASHRAE Standard 140, which consists of analytical verification, comparative testing, and empirical validation. Preliminary results using whole-building energy analysis show that careful analysis should be done when designing PCMs in homes, as their thermal performance depends on several variables such as PCM properties and location in the building envelope. Several studies have investigated different techniques to implement PCM in building components.

On the other hand, photovoltaic (PV) modules integration in the building sector is one of the effective and easiest application to improve the energy performance (Machniewicz et al. [9]). The PV modules on building façades and rooftops is an ideal application of solar electricity generators in the urban environmen, (Urbanetz et al. [10]). Tian et al. [1] have developed a PTEBU model to evaluate the effect of PV system on the microclimate of urban canopy layer and it was concluded that that PV roof and PV façade with ventilated air gap significantly change the building surface temperature and sensible heat flux density. Yoon at al. 12 have mentioned that Dye-sensitized solar cell (DSSC) is considered one of the most promising photovoltaic systems for building integration. Accordingly the relationship between the transparency, the PV efficiency and the overall energy efficiency of a building when DSSC is applied as window system have been investigated. It is shown that the efficiency of less 
transparent DSSC is generally higher due to higher short circuit current density (Jsc) from the thick electrode. The efficiency of PV modules depends on the solar radiation intensity and temperature of the panel (Ma. et al. [13]). Six basic techniques of PV thermal management could be identified: natural or forced air circulation, hydraulic or thermoelectric cooling, heat pipes and implementation of phase changing materials. Although the implementation of PCM on the back side of PV panel reduces and stabilizes its surface temperature (Pielichowska et al. [14]), the system, as a whole, needs a detailed analysis since that PCM thermal performance is depending on many uncontrolled dynamic conditions such as external temperature and wind speed (Brano et al. [15]). Elarga at al. in [16] and in [17] have highlighted that the correct choice of the transition temperature of the PCM, coupled with a synchronized ventilation strategies could ensure keeping the PCM under its melting/solidification phase i.e. the highest range of specific heat capacity values and accordingly higher working efficiency of PV-PCM modules.

\subsection{Background - Building optimization algorithms}

The analysis of the energy consumption in a building is complex and includes several parameters that could affect the performances, furhtermore, the parameters to be considered in an optimzation algorithm are diverse and overlapping. The necessity to implement cosimulation between different dynamic models is essential to obtain realistic results. Concerning the energy and indoor temperature variation (ITV) performance, the optimization should include set of parameters such as the effect of climate, building architectural design, ventilation schedule and control of energy storage systems. Several novel method/design tools have been developed for aiding the optimal building design ( $\mathrm{Lu}$ et al. [18]).De Gracia et al. [19] have investigated active thermal storage system TES applying a control system based on reinforcement learning technique. This proposed optimization algorithm has evaluated the system performance based on energy savings, cost reduction and $\mathrm{CO}_{2}$ mitigation under different climates condition which obtained a more realistic evaluation concerning the building sector development. Hamdy et al. 20] proposed a modified multi-objective optimization approach which is combined with IDA ICE (building performance simulation program) 21] to minimize the investment and the equivalent $\mathrm{CO}_{2}$ emissions for a family house including the HVAC system. Asadi et al. 22 have analyzed multiple choices for retrofitting a building implementing simulation-based multi-objective optimization scheme (a combination of TRNSYS, GenOpt and a Tchebycheff optimization technique developed in MATLAB) to optimize the retrofit 
cost, energy savings and indoor temperature varaiation compared to desgin tempeartures of a residential building.GenOpt is an optimization program for the minimization of a cost function that is evaluated by an external simulation program. However, GenOpt is not capable of handling multi-objective optimization. A Tchebycheff programming procedure has been developed in MATLAB to tackle the multi-objective optimization problem. A real case study is used to demonstrate the functionality of the proposed approach. The results verify the practicability of the approach and highlight that, by taking into consideration more possibilities available for building retrofit as well as more objectives for making the solving procedure extremely difficult and time-consuming. Ascione at al. 23 have proposed a simulation based model predictive control (MPC) procedure (EnergyPlus and MATLAB) consisting in the multi-objective optimization for operating cost and thermal comfort of a space conditioning system. The critical issue of huge computational time, typical of simulation-based MPC, is overcome by adopting a reliable minimum run period. Carlucci et al. 24 have implemented a multi-objective optimization to minimize thermal and visual discomfort, concluding that design procedures unsupported by automated optimization tools might find a hard challenge in exploring the entire space if variables and covering towards optimal solutions. Bambrook et al. 25 conducted a design optimization using a building energy simulation program IDA ICE for a detached low energy house in the mild warm Sydney climate. The aim of the optimization was to reduce the building heating and cooling demand to the level at which the heating and cooling system was no longer necessary. Wang et al. 26] investigated the optimal design solutions for zero energy building design in UK. Optimal design strategies and energy systems, including passive design parameters (external walls, window to wall ratios and orientations) and energy efficient mechanical systems as well as renewable energy systems, were provided by employing EnergyPlus and TRNSYS 16 simulation software. The weighing of the parameters on the under investigated objectives is one of the important aspects to be taken into consideration during the optimization phase. Bucking et al. 27] proposed a methodology to identify the influential variations on the building performance. A back-tracking search identified that 8 of 26 variables have significant effects on the net-energy consumption in a house casestudy, especially solar orientation, variables related to the sizing of a roof-based PV system and energy-related occupant behavior. Sun [28] studied the impacts of macro-parameters of buildings and systems (such as wall thickness, window to wall ratio, system COP) and their variations in a nearly zero energy buildings (nZEB) on the system design through a systematic 
95 factor in determining all building system sizes and the overall initial investment cost, followed by the system COP and internal gain intensity.

In the present work, the innovative integration of PV-PCM inside the cavity of double skin glazed facade [29] has taken a step forward. The PV-PCM calculation module is integrated in an optimization loop, based on genetic algorithms. The multi-objective optimization schema has been developped on the basis of S.O.C.R.A.TE. algorithm (Dal Monte et al. [30] and [31]) in order to force the creation and mutation operators of the MATLAB R2013b 32] gamultiobj algorithm to assume integer values in part of the genetic pool. The mathematical problem results in a mixed-integer optimization where two types of design variables are considered: the ventilation schedule variables assume values in an integer domain, the mass flow rates variables take values in a continuous domain. The objective behind the optimization analysis is to identify the best combination of parameters such as the schedule and duration of ventilation inside the air cavities and the starting ventilation hours during three different periods of the year (winter, summer and mid seasons) to improve the chosen fitness functions represented by two conflicting objectives which are the thermal loads and the indoor temperature variation. It is important to highlight that indoor temperature variation term is defined as the difference between the operating and the design temperature values.

\section{Methodology}

The overall approach of the present numerical study is concluded in employing finite difference method FDM, fixed nodal grid and thermal resistances techniques to describe the different façade solutions under investigation. The methodology section is subdivided into five parts. The first gives a brief introduction to the thermal resistance method implemented to simulate different glazed/PV modules. The second is discussing numerical model of the PV integrated façade, the third is dedicated to describe the PCM integration to PV façade module. Following this, an illustration of how to couple the two numerical models (TRNSYS 16 and MATLAB R2013b) is given. Finally the genetic optimization algorithm is clarified.

\subsection{Brief introduction to thermal resistances method}

In this section a brief explanation on how to model the glazed and PV elements composing the façade external module via 1-dimensional nodal grid is given. The nodes are connected by 
a group of thermal resistances $R_{k}, R_{c}$ and $R_{\text {rad }}$ represents respectively conduction, convection, and radiation heat transfer. Thermal resistances are determined respectively through equations 1. 2 , and 6 .

$$
R_{k}=x / k
$$

where $x$ is thickness and $k$ is thermal conductivity.

$$
R_{c}=1 / h_{c}
$$

where $h_{c}$ is the convection heat transfer coefficient.

On the other, the convection heat transfer through multiple skin façade occurs in different modes which are necessary to be taken into consideration. The three different modes are a) between the external layer and outside, b) the inner layer and inside and c) the forced ventilated cavity. The empirical laws to estimate the convection heat transfer coefficient CHTC are:

a) Outdoor layer the McAdams correlation [33] was adopted;

$$
h_{o}=5.62+3.9 v
$$

b) Indoor layer, the convection heat transfer is evaluated using equation 4 , 34

$$
h_{i}=\left\{\left[1.5\left|\frac{\Delta T}{h_{f}}\right|^{0.25}\right]^{6}+\left[1.23(\Delta T)^{0.33}\right]^{6}\right\}^{1 / 6}
$$

where $\Delta T$ is the difference between the indoor air temperature and the indoor surface temperature, while $h_{f}$ is the floor height.

c) Inside the forced ventilated cavity $N_{u}$ equation 5 is employed [35]:

$$
N_{u}=\left(0.037\left(R_{e}\right)^{0.8}-871\right) \operatorname{Pr}^{1 / 3}
$$

where, $N_{u}=$ Nusselt number, $R_{e}=$ Reynolds number, $P_{r}=$ Prandtl number. 
The radiation heat exchange $R r$ is identified by equation 6 and the radiation heat transfer coefficnet is represented in equation 7 [35].

$$
R_{r}=1 / h_{r}
$$

The $h_{r}$; is the radiation heat transfer coefficient equals:

$$
h_{r}=\frac{\left.4 \sigma\left(T_{a v g}\right)^{3}\right]}{\left(\frac{1}{\varepsilon_{1}}+\frac{1}{\varepsilon_{2}}-1\right)}
$$

where $T_{\text {avg }}$ is the average temperature of the two opposite surfaces, which has been evaluated as function of nodal temperature in the previous time step values i.e. implicit solution [36].

\subsubsection{Overall approach}

The solution of the overall approach could be summarized in deriving energy balance equations for each node. Later, all equations are solved simultaneously employing a finite difference technique to estimate the heat transfer mechanism. In the numerical model, the solution domain is defined by finite number of grid points in which the derived linear equations form a matrix system as shown in equation 8 , where $A$ is the matrix of coefficients, $X$ is the vector of unknowns and $B$ is the column vector of known terms. The system is solved by inverting the matrix to obtain the unkonown temperature values $X$. More details related to the numerical modelling techniquecs are found in [37] and 38.

$$
A * X=B
$$

\section{2. $P V$ integrated façade}

The section illustrates how to model the PV integrated façade in order to include it in the exploratory investigation to evaluate the influence of PCM integration to PV integrated buildings PVIB. The fixed grid is represented by eight nodes and the coupling between the fixed grid model, developed on MATLAB, to TRNSYS is further discussed in Section 2.4. Optical and physical characteristics of the PV module are clarified in Table 1.

\subsubsection{Description of the mathematical model}

The mathematical model is consists of a sequence of 8 nodes representing elements of PV 


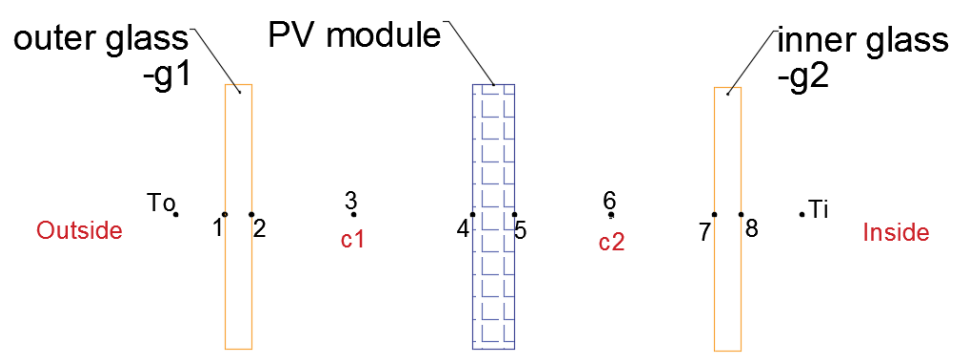

Figure 1: Representation of the PV configuration scheme.

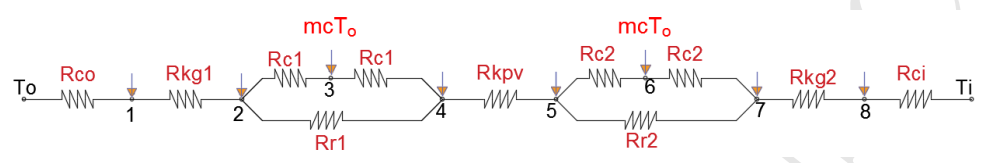

Figure 2: Representation of the RC model.

Table 1: PV technical specifications

\begin{tabular}{|l|l|}
\hline Cell type & a-si thin film \\
\hline Front glass & $6 \mathrm{~mm}$ tempered glass \\
\hline Rear glass & $6 \mathrm{~mm}$ tempered glass \\
\hline PV glass & 3.2 float glass \\
\hline Sol. Transmission & $7.4 \%$ \\
\hline Sol. Reflection & $10.2 \%$ \\
\hline
\end{tabular}

between nodes are shown, where $R_{c o}, R_{c i}$ are the convection heat transfer coefficients between external layer/outside and internal layer/inside ambient conditions respectively. $R_{k g 1}, R_{k g p v}$ and $R_{k g 2}$ are conductive resistances for glass $g 1, \mathrm{PV}$ module and glass $g 2$.

In nodes 1 and 8 , the heat transfer through the outer and inner layers of the glazed façade respectively is described by two thermal resistances, the convection heat transfer with the ambient conditions and the conduction transfer within the glazed layer itself. The right hand side of all energy equations includes the transmitted solar radiation $I_{t r}$ multiplied by the solar absorption coefficient $a_{g}$ of the glazed layer under investigation.

Node (1):

$$
\left(-\frac{k_{g l}}{x_{g 1}}-h_{o}\right) T_{1}+\left(\frac{k_{g l}}{x_{g 1}}\right) T_{2}=-I_{t r 1}\left(\frac{a_{g 1}}{2}\right)-\left(T_{o} h_{o}\right)
$$


Node (8):

$$
\left(\frac{k_{g 2}}{x_{g 2}}\right) T_{7}+\left(-h_{1}-\frac{k_{g 2}}{x_{g 2}}\right) T_{8}=-I_{t r 3}\left(\frac{a_{g 2}}{2}\right)-\left(T_{i} h_{i}\right)
$$

Nodes 2, 4, 5 and 7 are representing glazed layers and PV module opposed surfaces. In these nodes, the energy balance equations from 11 to 14 respectively are including thermal resistances of conductivity, $I_{t r}$ solar radiation and convection heat transfer.

Node (2):

$$
\left(\frac{k_{g 1}}{x_{g 1}}\right) T_{1}+\left(-\frac{k_{g 1}}{x_{g 1}}-h_{C 1}-h_{r}-\right) T_{2}+h_{C 1} T_{3}+h_{r} T_{4}=-I_{t r 1}\left(\frac{a_{g 1}}{2}\right)
$$

Node (4):

$$
\left(\frac{k_{p v}}{x_{p v}}\right) T_{5}+\left(-\frac{k_{p v}}{x_{p v}}-h_{C 1}-h_{r}-\right) T_{4}+h_{C 1} T_{3}+h_{r} T_{2}=-I_{t r 2}\left(\frac{a_{p v}}{2}\right)
$$

Node (5):

$$
\left(\frac{k_{p v}}{x_{p v}}\right) T_{4}+\left(-\frac{k_{p v}}{x_{p v}}-h_{C 2}-h_{r}-\right) T_{5}+h_{C 2} T_{6}+h_{r} T_{7}=-I_{t r 2}\left(\frac{a_{p v}}{2}\right)
$$

Node (7):

$$
\left(\frac{k_{g 3}}{x_{g 3}}\right) T_{8}+\left(-\frac{k_{g 3}}{x_{g 3}}-h_{C 2}-h_{r}-\right) T_{7}+h_{C 2} T_{6}+h_{r} T_{5}=-l_{t r 3}\left(\frac{a_{g 2}}{2}\right)
$$

Nodes 3 and 6 are used to describe the two air cavities ( $c 1$ and $c 2)$ which are seperated by the PV module [39. The cavities ventilation is out to out technique, i.e. air comes form outside, ventilates the cavity and is exhausted to the outside again. External air temperature value $T_{o}$ for each time step $(15 \mathrm{~min})$ is compensated in the equations 15 and 16.

Node (3):

$$
h_{C 1} T_{2}+\left(-2 h_{C 1}-\dot{m} c\right) T_{3}+h_{C 1} T_{4}=-(\dot{m} c) T_{o}
$$


Node (6):

$$
h_{C 2} T_{5}+\left(-2 h_{C 2}-\dot{m} c\right) T_{6}+h_{C 2} T_{7}=-(\dot{m} c) T_{o}
$$

\section{3. $P V-P C M$ model}

In this subsection, the enthalpy numerical method which describes thermal performance of PCM is brielfy presented. Later the energy balance equations describing the PV-PCM fixed grid model are shown. However, the enthalpy method has been previously illustrated and validated against experimantal data [16. For more details concerning the experimental campaign, reader should refer to [40].

The enthalpy method was proposed by Voller and Swaminathan [41, to model the thermal behaviour of materials undergoing a phase change, under the assumption that phase change occurs over an arbitrarily narrow temperature range. In this way, the enthalpy can be related to the temperature by a piecewise continuous function. Assuming constant specific heat capacity in each phase, the enthalpy can be approximated using three temperature possibility ranges as in equation 17

$$
H= \begin{cases}c_{s} T & \text { if } T \leq T_{m}-\varepsilon \\ c_{s}\left(T_{m}-\varepsilon\right)+\left[\frac{c_{s}+c_{l}}{2}+\frac{L}{2 \varepsilon}\right]\left(T-T_{m}+\varepsilon\right) & \text { if } T_{m}-\varepsilon \leq T \leq T_{m}+\varepsilon \\ c_{l} T+\left(c_{s}-c_{l}\right) T_{m}+L & \text { if } T \geq T_{m}+\varepsilon\end{cases}
$$

Where $\varepsilon$ is an arbitrarily small value representing half the phase change temperature to temperature.

$$
C^{A}=\frac{d H}{d T}= \begin{cases}c_{s} & \text { if } T \leq T_{m}-\varepsilon \\ {\left[\frac{c_{s}+c_{l}}{2}+\frac{L}{2 \varepsilon}\right]\left(T-T_{m}+\varepsilon\right)} & \text { if } T_{m}-\varepsilon \leq T \leq T_{m}+\varepsilon \\ c_{l} & \text { if } T \geq T_{m}+\varepsilon\end{cases}
$$

The definitions of $H(T)$ and $C^{A}$ can be used to linearise the discritized enthalpy equation in an iterative form, as in equation 19 .

$$
a_{n_{b}} T_{n_{b}}-\left(a_{p}+\rho C^{A}\right)\left(T_{P}\right)^{n}=a_{p} \rho C^{A}\left(T_{P}\right)^{n-1}-\rho \frac{V}{\Delta \tau}\left[H_{p}^{\circ}-H_{p}^{n-1}\right]
$$


where $H_{p}^{\circ}$ is the enthalpy node value of the previous time step, $H_{p}^{n-1}$ represents the enthalpy node value of iteration $n-1, a$ are the nodal coefficients and $\tau$ is the time step.

The solution domain is defined where the derived linear equations form a matrix system, which is instantaneously solved by inverting the matrix to obtain the temperature values according to an iterative scheme. The initial values of each time step are represented by the converged solution of the previous time step. From the known temperature field and enthalpy at iteration $n-1$, the temperatures in each node are updated. In order to ensure solution consistency, a correction and iterative loop has to be followed by saving the solution of the matrix in the previous iteration and then re-solving the system after correcting the nodal temperature $T_{P}^{n}$ by equation 20 with three possibilities of enthalpy ranges until the convergence is reached. The code thus saves the calculated temperature field, and starts a new time step.

$$
T_{P}^{n}= \begin{cases}\left(\frac{H_{P}^{n}}{c_{s}}\right) & \text { if } H_{P}^{n} \leq c_{s}\left(T_{m}-\epsilon\right) \\ \left(\frac{H_{P}^{n}+\left[\frac{c_{s}+c_{l}}{2}+\frac{L}{2 \varepsilon}\right]\left(T_{m}-\varepsilon\right)}{\frac{c_{s}+c_{l}}{2}+\frac{L}{2 \varepsilon}}\right) & \text { if } c_{s}\left(T_{m}-\epsilon\right) \leq H_{P}^{n} \leq c_{s}\left(T_{m}+\epsilon\right) \\ \frac{H_{P}^{n}-\left(c_{s}-c_{l}\right) T_{m}-L}{c_{l}} & \text { if } H_{P}^{n} \geq c_{s}\left(T_{m}+\epsilon\right)+L\end{cases}
$$

\subsubsection{Description of the mathematical model}

In the PV-PCM mathematical model a scheme composed by 15 nodes is adopted, as shown in Figures 3 and 4 , where $R_{k p}$ represents thermal conductivity resistance of PCM node.

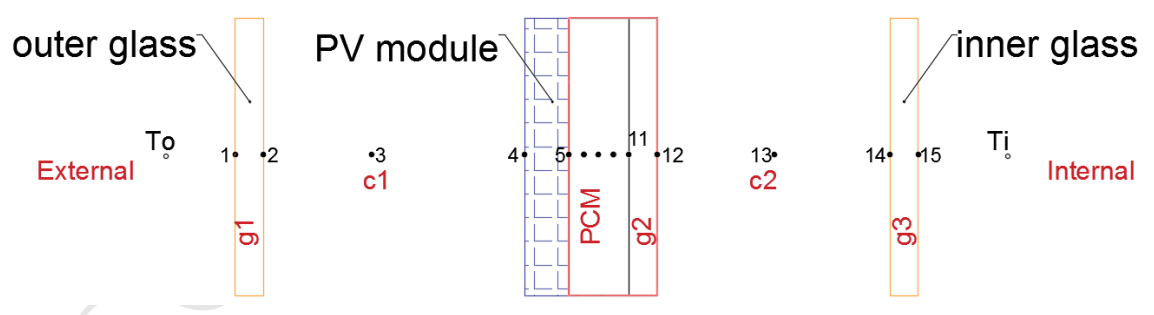

Figure 3: Representation of the PV-PCM facade configuration scheme.

Thermal conduction and convection resistances are moderating the thermal performance of the external/internal nodes 1 and 15, equations 21 and 22 respectively.

$$
\left(-\frac{K_{g l}}{x_{g 1}}-h_{o}\right) T_{1}+\left(\frac{K_{g l}}{x_{g 1}}\right) T_{2}=-I_{t r 1}\left(\frac{a_{g 1}}{2}\right)-\left(h_{o} T_{o}\right)
$$




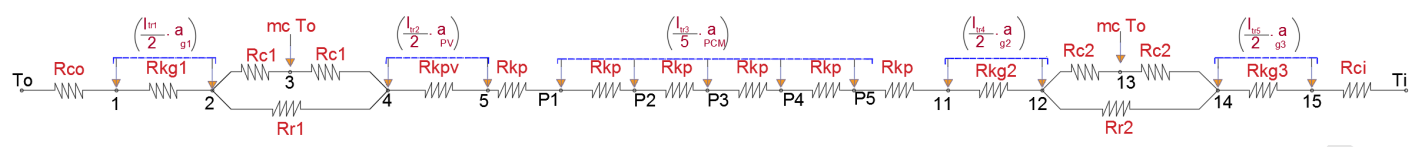

Figure 4: Representation of the RC scheme.

$$
\left(-\frac{K_{g 3}}{x_{g 3}}-h_{i}\right) T_{15}+\left(\frac{K_{g l}}{x_{g 1}}\right) T_{14}=-I_{t r 5}\left(\frac{a_{g 1}}{2}\right)-\left(h_{i} T_{i}\right)
$$

Radiation heat exchange between surfaces is appeared in the energy balance between nodes 2, 4 and between 12 and 14 .

Node (2):

$$
\left(\frac{K_{g 1}}{x_{g 1}}\right) T_{1}+\left(-\frac{K_{g l}}{x_{g 1}}-h_{C 1}-h_{r}\right) T_{2}+h_{C 1} T_{3}+h_{r} T_{4}=-I_{t r 1}\left(\frac{a_{g 1}}{2}\right)
$$

Node (4):

$$
h_{r} T_{2}+h_{C 1} T_{3}+\left(-h_{r}-h_{C 1}-\frac{k_{p v}}{x_{p v}}\right) T_{4}+\left(\frac{k_{p v}}{x_{p v}}\right) T_{5}=-I_{t r 2}\left(\frac{a_{p v}}{2}\right)
$$

Node (12):

$$
\left(\frac{k_{g 2}}{x_{g 2}}\right) T_{11}+\left(-h_{r}-h_{C 2}-\frac{k_{g 2}}{x_{g 2}}\right) T_{12}+h_{C 2} T_{13}+h_{r} T_{14}=-I_{t r 4}\left(\frac{a_{g 2}}{2}\right)
$$

Node (14):

$$
\left(\frac{K_{g 3}}{x_{g 3}}\right) T_{15}+\left(-\frac{K_{g 3}}{x_{g 3}}-h_{C 2}-h_{r}\right) T_{14}+h_{C 2} T_{13}+h_{r} T_{12}=-I_{t r 5}\left(\frac{a_{g 3}}{2}\right)
$$

Forced convection was implemented within both cavities represented by node 3 and 13 in equations 27 and 28 respectively.

$$
\begin{gathered}
h_{C 1} T_{2}+\left(-2 h_{C 1}-\dot{m} c\right) T_{3}+h_{C 1} T_{4}=-(\dot{m} c) T_{o} \\
h_{C 2} T_{12}+\left(-2 h_{C 2}-\dot{m} c\right) T_{13}+h_{C 2} T_{14}=-(\dot{m} c) T_{o}
\end{gathered}
$$

In Nodes 5 and 11 thermal conductivity is the only heat transfer mode dominating the energy balance. 
Node (5):

$$
\left(\frac{k_{p v}}{x_{p v}}\right) T_{4}+\left(-\frac{k_{p v}}{x_{p v}}-\frac{k_{p 1}}{x_{p 1}}\right) T_{5}+\left(\frac{k_{p 1}}{x_{p 1}}\right) T_{p 1}=-I_{t r 2}\left(\frac{a_{p v}}{2}\right)
$$

Node (11):

$$
\left(\frac{k_{p 5}}{x_{p 5}}\right) T_{p 5}+\left(-\frac{k_{p 5}}{x_{p 5}}-\frac{k_{g 2}}{x_{g 2}}\right) T_{11}+\left(\frac{k_{g 2}}{x_{g 2}}\right) T_{12}=-I_{t r 4}\left(\frac{a_{g 2}}{2}\right)
$$

Each homogeneous sub layer from the five nodes composing PCM layer (nodes from P1 to and MATLAB models occurs in air node 13 (see Figure 4). The estimated transmitted solar radiation and air temperature with a 15 minutes time step are read as a user defined value for the inner layer zone on TYPE56. The reason behind considering the coincident interface between 
the two models in node 13 is that to obtain the correct inner glazed surface energy balance and its final temperature, the complete room structure and the correspondent radiative/convective heat exchange between all room inner surfaces(which includes also thermal storage of the room walls) have to be considered. The inner glass layer has been identified in TRNbld TYPE56 library with the specifications of Table 2 .

\begin{tabular}{|c|c|}
\hline Density & $2500 \mathrm{~kg} / \mathrm{m}^{3}$ \\
\hline Capacity & $0.84 \mathrm{~kJ} /(\mathrm{kgK})$ \\
\hline Conductivity & $0.27 \mathrm{~kJ} /(\mathrm{hmK})$ \\
\hline
\end{tabular}

Table 2: Glazed layer specifications

The inside set temperatures, adopted in the analysis, for the summer and winter seasons are defined in Table 3 . The considered façade is west oriented, with an area of $70 \mathrm{~m}^{2}$ (3.5m height, $20 \mathrm{~m}$ width). The office area is $80 \mathrm{~m}^{2}$ and internal loads were evaluated as $24 \mathrm{~W} / \mathrm{m}^{2}$. All internal walls were considered adjacent to other offices with the same design set of temperature.

\begin{tabular}{|c|c|c|c|}
\cline { 2 - 4 } \multicolumn{1}{c|}{} & Period & Working days & Weekend \\
\hline \multirow{2}{*}{ Cooling season } & Working hours (07:00 19:00) & $25^{\circ} \mathrm{C}$ & $29^{\circ} \mathrm{C}$ \\
\cline { 2 - 4 } & Idle hours (19:00 07:00) & $32^{\circ} \mathrm{C}$ & $32^{\circ} \mathrm{C}$ \\
\hline \multirow{2}{*}{ Heating season } & Working hours (07:00 19:00) & $20^{\circ} \mathrm{C}$ & $17^{\circ} \mathrm{C}$ \\
\cline { 2 - 4 } & Idle hours (19:00 07:00) & $15^{\circ} \mathrm{C}$ & $15^{\circ} \mathrm{C}$ \\
\hline
\end{tabular}

Table 3: Inside Set Temperature 


\begin{tabular}{|c|c|}
\hline $\mathbf{P C M}(\mathbf{3 5 R T})$ & \\
\hline Solid temperature (lower limit of phase change range) & $34{ }^{\circ} \mathrm{C}$ \\
\hline Nominal, melting temperature & $35^{\circ} \mathrm{C}$ \\
\hline Liquid temperature (upper limit of phase change range) & $36^{\circ} \mathrm{C}$ \\
\hline Specific heat capacity & $2 \mathrm{~kJ} \mathrm{~kg}^{-1} \mathrm{~K}^{-1}$ \\
\hline Latent heat of fusion & $160 \mathrm{kJkg}^{-1}$ \\
\hline Max. Operation Temperature & $70{ }^{\circ} \mathrm{C}$ \\
\hline Density Liquid, $40^{\circ} \mathrm{C}$ & $0.77 \mathrm{kgl}^{-1}$ \\
\hline Density Solid, $25^{\circ} \mathrm{C}$ & $0.88 \mathrm{kgl}^{-1}$ \\
\hline
\end{tabular}

Table 4: Physical characteristics of PCM

\subsection{Genetic Algorithm Optimization}

Genetic algorithms represent one of the most powerful tool to analyse problems characterized by the influence of several parameters that lead to the definition of multiple optimal solutions. The representation of the optimization schema adopted for the proposed analysis is shown in Figure 5. The overall optimization is lead by MATLAB gamultiobj algorithm; the genes represent the parameters for the PV-PCM façade calculation (carried in MATLAB) and the resulting distributions of the cavity air node temperature $T_{a c}$, transmitted solar energy $I_{t r}$ and cavity convection heat transfer coefficient $h_{C}$ are saved. The inner zone calculation, implemented in the TRNSYS module, uses the previous distributions in order to evaluate the thermal load $Q_{t h}$ and the operating temperature $T_{o p}$ evolutions in each time step of the year. In the second MATLAB module, different in-house functions elaborate the data in order to determine two single parameter value to describe the performances of the individual.

The population adopted for optimization consists of 40 individuals composed by a set of 8 genes; the optimization run for a total number of 50 generations. The first population considered in the algorithm is random initialized.

\subsubsection{Design Variables}

In the optimization terminology, an individual represents the codification of a certain setting of the analysis and the resulting performances are calculated starting from its parameters; furthermore, the individual's chromosome consists of the sequence of parametric values to be optimized. 


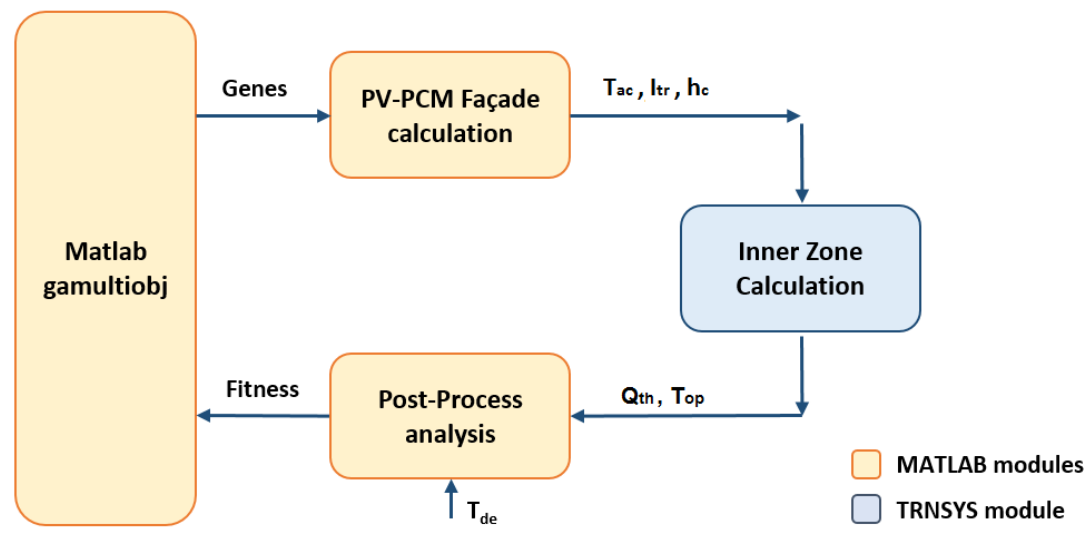

Figure 5: Schematic representation of the genetic algorithm.

In the present optimization, the considered design variables (defined with the $X$ array, illustrated in Table 5) determines the schedule of the ventilation inside the two cavities; genes $X(1)$ and $X(2)$ represent the mass flow values multiplied by the air specific heat capacity $\left(m c_{p 1}\right.$ and $m c_{p 2}$ in $\left.[\mathrm{J} / \mathrm{sK}]\right)$, in genes from $X(3)$ to $X(5)$ the starting hour of the ventilation system is fixed for Winter, Mid-Seasons and Summer; finally genes from $X(6)$ to $X(8)$ establish the duration of the ventilation during the three periods. The parameters that determine the schedules of ventilation are represented by an integer number: the values are further converted in a starting hour or a duration using a factor of 30 minutes. For instance, the ventilation in winter of the baseline individual ( $3^{\text {rd }}$ row of Table 5 ) starts at 8.00a.m. $(16 * 0.5 h$, Gene $X(3))$ and is turned off after 8 hours $(16 * 0.5 h$, Gene $X(3))$.

\begin{tabular}{|l|c|c|c|c|c|c|c|c|}
\cline { 2 - 9 } \multicolumn{1}{c|}{} & $\mathbf{X}(\mathbf{1})$ & $\mathbf{X}(\mathbf{2})$ & $\mathbf{X}(\mathbf{3})$ & $\mathbf{X}(\mathbf{4})$ & $\mathbf{X}(\mathbf{5})$ & $\mathbf{X}(\mathbf{6})$ & $\mathbf{X}(\mathbf{7})$ & $\mathbf{X}(\mathbf{8})$ \\
\hline Lower Bounds & 60 & 60 & 0 & 0 & 0 & 0 & 0 & 0 \\
\hline Upper Bounds & 360 & 360 & 48 & 48 & 48 & 20 & 20 & 20 \\
\hline Baseline & 100 & 100 & 16 & 16 & 16 & 16 & 16 & 16 \\
\hline
\end{tabular}

Table 5: Upper and lower bounds adopted for the design variables, chromosome of the baseline individual considered for the optimization.

\subsubsection{Objective Functions and Constraints}

The optimization problems concerns the minimization of two conflicting objective functions. The first objective function $f_{Q}$ is represented by the ratio between the total thermal load of a 
year, of the considered individual and the baseline setting, calculated as:

$$
f_{Q}=\frac{\sum_{i=1}^{n}\left|Q_{t h, i}\right|}{Q_{t h, \text { bas }}}
$$

The ITV $f_{\Delta T}$ is the second objective function. In the present formulation, it is defined as the differences between the calculated operating temperature $T_{o p}$ and the desired design temperature $T_{d e}$ in order to guarantee the minimal deviation from the ideal trend of temperature. The value is normalized with respect the value of the baseline configuration:

$$
f_{\Delta T}=\frac{\sum_{i=1}^{n}\left|T_{o p, i}-T_{d e, i}\right|}{\Delta T_{b a s}}
$$

The calculated values for the baseline configuration are: $Q_{t h, b a s}=33220 \mathrm{kWh}$ and $\Delta T_{\text {bas }}=97679 \mathrm{~K}$; these values represent the summation of the thermal loads and differences in temperatures during one year.

Furthermore, a linear inequality constraint is set in order to limit the sum of mass flow rate multiplied by the air specific heat capacity $m c_{p}$ in cavities 1 and 2 to $400 J . s^{-1} K^{-1}$, i.e. $0.4 \mathrm{~kg} \cdot \mathrm{s}^{-1}$.

$$
X(1)+X(2) \leq 400
$$

The choice of using two contrasting functions allows to determine a Pareto front and to identify several solutions, based on the importance given to the considered objectives.

\section{Results and Discussion}

The results are divided into two main sections; first, the baseline configuration with and without PCM is presented in order to highlight the effect of PCM on the performance, the second section contains the results of the optimization and different individuals belonging to the Pareto Front are analysed.

\subsection{Exploratory analysis: $P V$ with and without PCM integrated façade}

For a complete test reference year data TRY, two simulations were run considering cases with and without PCM. Forced ventilation system is assumed, the air flow rate from external ambinet for both cavities were considered $10 \mathrm{l} / \mathrm{s}$ per façade meter [44, 45] and it was ON 
during working hours, which started from 7.00 to 19.00. The inside set temperatures have been previously specified in Table 3

Thermal analysis has been investigated for both cases to highlight the influence of the PCM latent heat storage capability. In Figure 6 the thermal energy profile for the week of $16^{\text {th }}-23^{\text {th }}$ of July is presented; in fact, according to the TRY database, this month is recorded as the hottest month in Venice summer season. As it is shown, thermal cooling loads are always higher during the day working hours. The implementation of PCM reduced thermal cooling loads all over the summer season by $48 \%$.

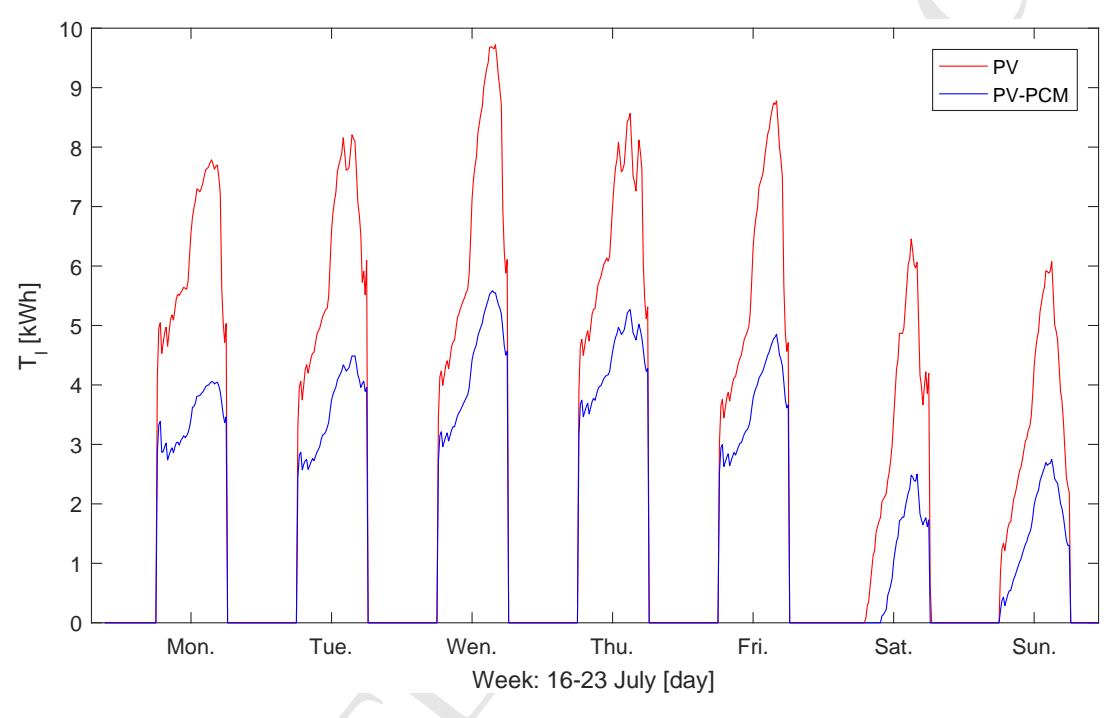

Figure 6: Week thermal energy profiles.

This initial exploratory study is followed by the optimization analysis to determine which are the parameters that influence on the PCM performance.

\subsection{Optimization Analysis}

\subsubsection{Analysis of Genetic Algorithm results}

The results of the optimization of the PV-PCM façade configuration are presented in terms of Pareto front analysis. The evolution of the Pareto front through the generation is shown in Figure 7f as can be noticed, the genetic algorithm greatly improved the performances of the individual until the 30th generation, after that, the convergence seems to be reached and no further improvements are found. On the other hand, Figure 8 presents an overview of the 
optimization in terms of Pareto front scheme where the blue points indicate all the calculated individuals, hence all the configurations tested by the optimization algorithm. While, the red line is connecting the set of individuals belonging to the overall Pareto front: some of these individuals have been taken into account in the analysis of the results.

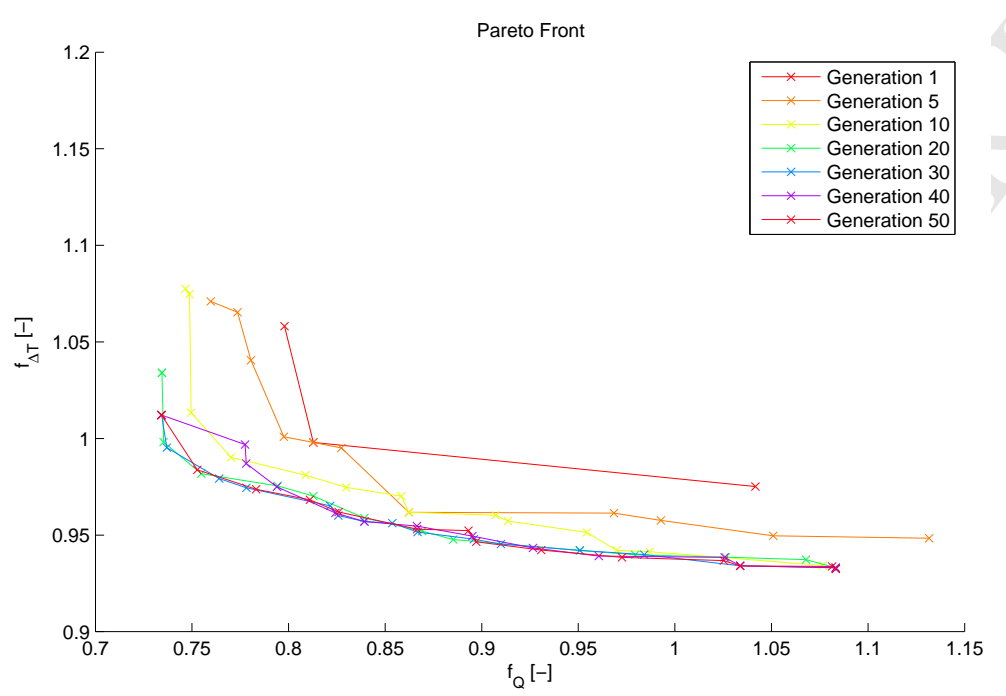

Figure 7: Evolution of the Pareto front through the generations.

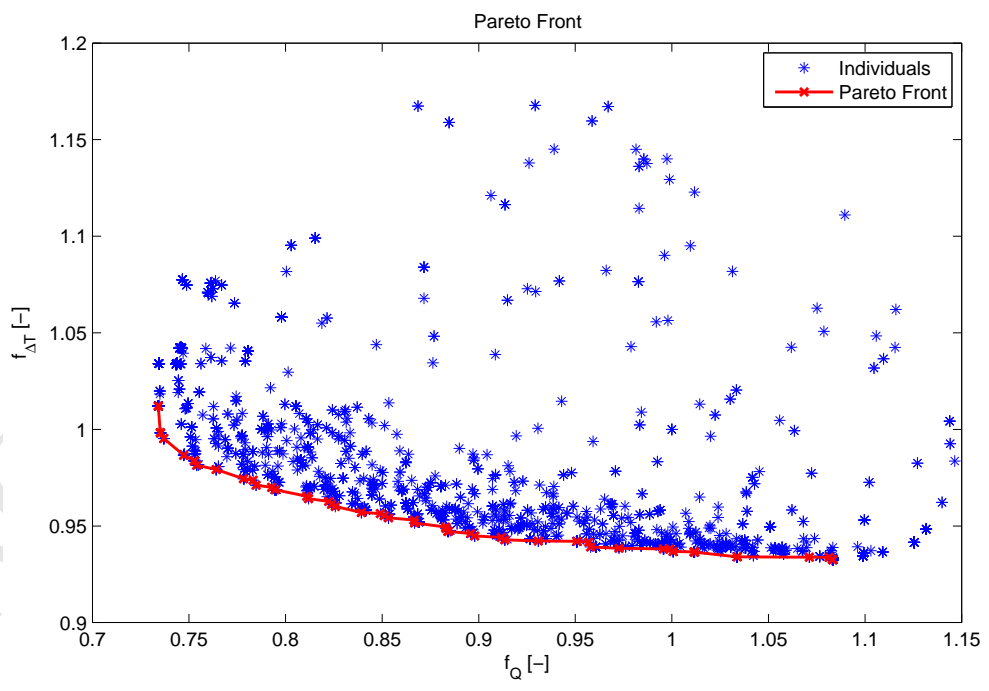

Figure 8: Final Pareto front of the optimization. 


\begin{tabular}{|l|c|c|c|c|c|c|c|c|c|c|}
\cline { 2 - 12 } \multicolumn{1}{c|}{} & $\mathbf{X}(\mathbf{1})$ & $\mathbf{X}(\mathbf{2})$ & $\mathbf{X}(\mathbf{3})$ & $\mathbf{X}(\mathbf{4})$ & $\mathbf{X}(\mathbf{5})$ & $\mathbf{X}(\mathbf{6})$ & $\mathbf{X}(\mathbf{7})$ & $\mathbf{X}(\mathbf{8})$ & $\boldsymbol{f}_{\boldsymbol{Q}}$ & $\boldsymbol{f}_{\boldsymbol{\Delta} \boldsymbol{T}}$ \\
\hline Basel. & 100.00 & 100.00 & 16 & 16 & 16 & 16 & 16 & 16 & 1.000 & 1.000 \\
\hline Ind01 & 158.25 & 106.96 & 13 & 19 & 15 & 1 & 16 & 20 & 0.734 & 1.012 \\
\hline Ind02 & 166.61 & 104.81 & 11 & 20 & 15 & 2 & 17 & 20 & 0.735 & 0.998 \\
\hline Ind03 & 186.37 & 106.12 & 9 & 19 & 15 & 4 & 19 & 19 & 0.754 & 0.981 \\
\hline Ind04 & 186.11 & 106.74 & 9 & 19 & 15 & 5 & 19 & 17 & 0.785 & 0.971 \\
\hline Ind05 & 181.54 & 106.42 & 10 & 19 & 15 & 4 & 19 & 14 & 0.826 & 0.960 \\
\hline Ind06 & 183.76 & 106.75 & 10 & 19 & 15 & 4 & 19 & 11 & 0.867 & 0.951 \\
\hline Ind07 & 176.60 & 106.58 & 10 & 19 & 15 & 5 & 19 & 6 & 0.958 & 0.939 \\
\hline Ind08 & 162.41 & 106.11 & 15 & 18 & 16 & 11 & 20 & 5 & 1.083 & 0.932 \\
\hline
\end{tabular}

Table 6: Genetic pool and fitness values of the considered individuals belonging to the Pareto front.

Individuals belonging to the front represent the best solutions in, at least, one objective function of the optimization. A single solution can not be considered as the best configuration, hence several individuals distributed along the front are hereby analysed. Table 6 compares the genetic pools and the fitness values of the considered individuals belonging to the Pareto front and the baseline configuration.

The first solutions to be discussed are located in the upper-left part of the Pareto front, they represent the best configuration for the thermal load reduction with no significant improvements in the ITV (Figure 9p). The setting of Ind01 allows the greatest reduction in the thermal load $f_{Q}$ $(-26.4 \%)$, however $f_{\Delta T}$ has been slightly increased of $1.2 \%$. Ind02 presents similar performances in terms of $f_{Q}$ with Ind01 and almost the same $f_{\Delta T}$ of the baseline. It is interesting to notice how the greatest reductions in thermal load have been obtained with the limitation of the ventilation time in winter season to 1 and 2 hours; it can be concluded the ventilation in winter is not necessary to improve the thermal load performance.

Moving along the Pareto Front towards right, the solutions improve the performances in terms of $f_{\Delta T}$ and at the same time get worse considering $f_{Q}$. Great increments in thermal load can be observed for Ind03 (-24.6\%) and Ind04 (-21.5\%) with small improvements in $f_{\Delta T}$ (Figure 10). As can be seen in Figure 11 improvements in thermal load are reduced for Ind05 ($17.4 \%)$ and Ind06 (-13.3\%) however the ITV decreases, being the operating temperature closer to the design temperature (decrease of $4.0 \%$ and $4.9 \%$ in $f_{\Delta T}$ ). 

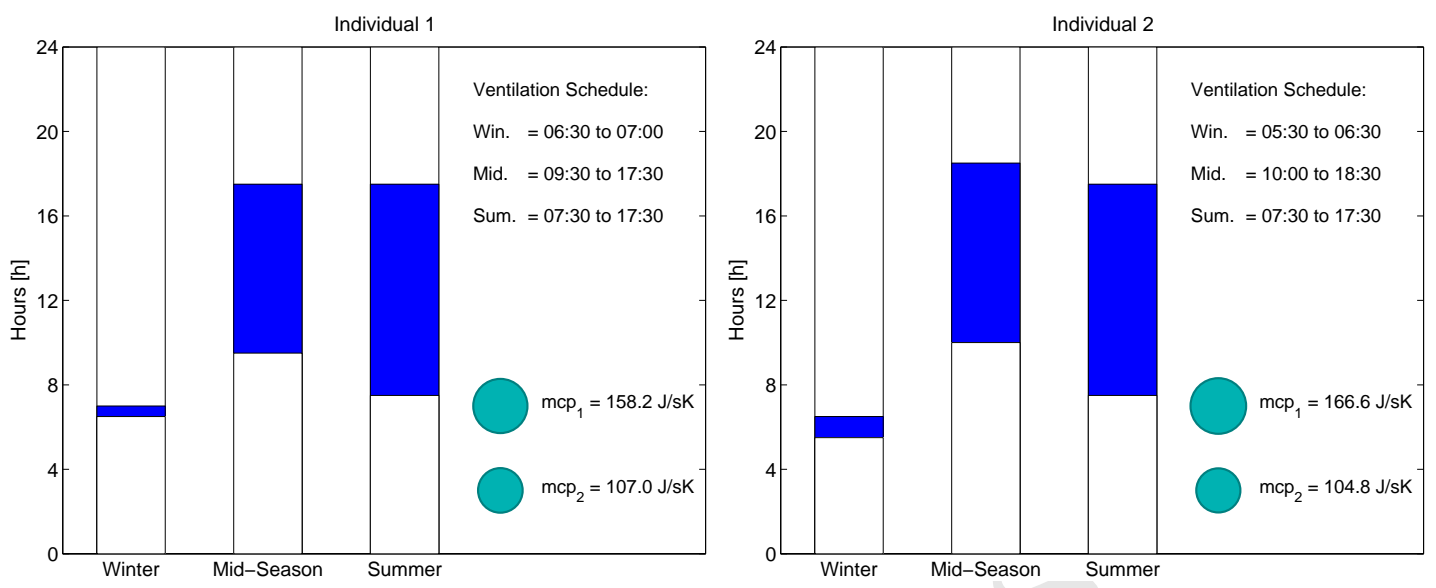

Figure 9: Graphical representation of the schedule of Individuals 1 (on the left) and 2 (on the right).
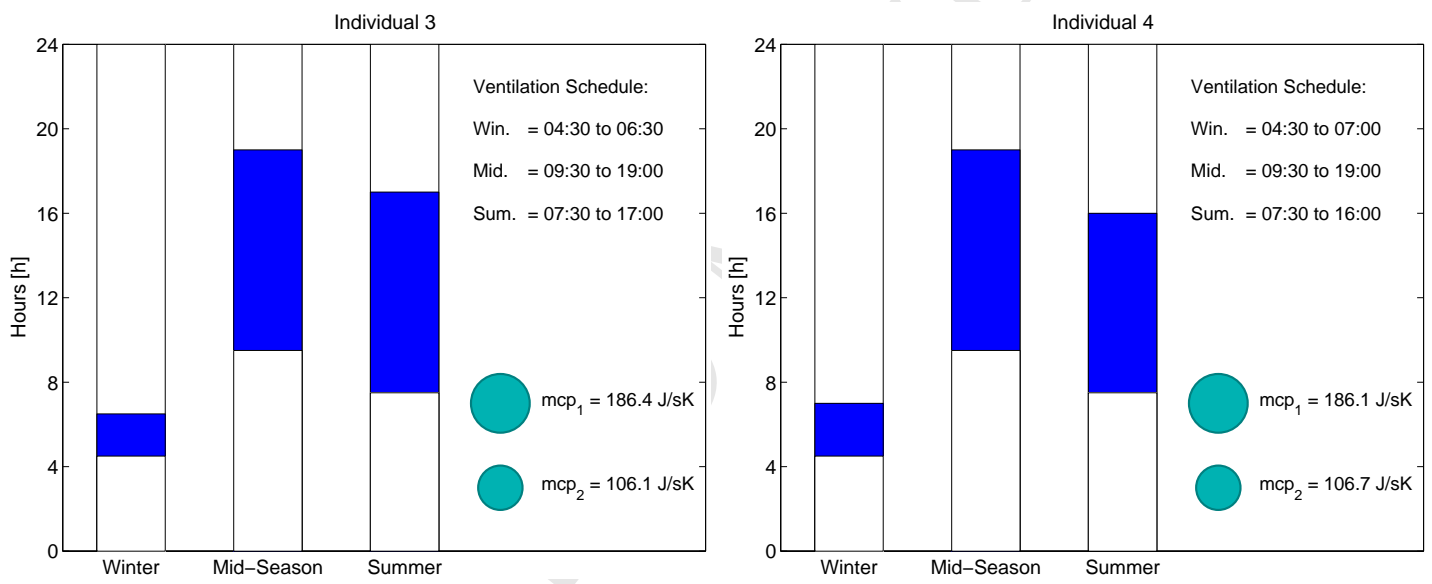

Figure 10: Graphical representation of the schedule of Individuals 3 (on the left) and 4 (on the right).

Finally, the last two considered individuals are found in the down-right zone of the Pareto Front (Figure 12). Ind07 improves $f_{\Delta T}$ of $6.1 \%$ with a limited reduction of thermal load of $4.2 \%$. The best individual of the optimization for the reduction of $f_{\Delta T}(-6.8 \%)$ is represented by Ind08, however its performance, in terms of $f_{Q}$, is decreased compared to the baseline, with an increment in thermal load of $8.3 \%$.

Some considerations can also be done observing the trend of parameters along the Pareto front (from Ind01 to Ind08). The slightly progressive increment in the ventilation duration during the winter season is opposed to the marked decrease in the Summer season. A clear trend in the parameters can be identified: thermal loads were decreased by limiting the ventilation 

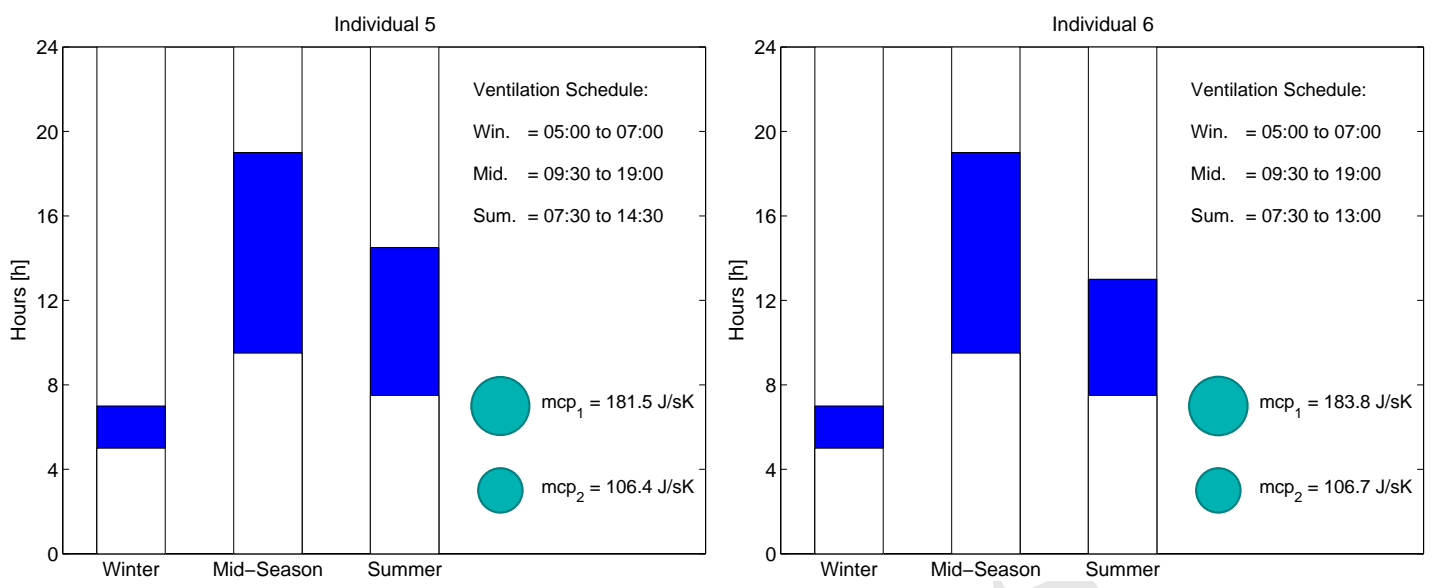

Figure 11: Graphical representation of the schedule of Individuals 5 (on the left) and 6 (on the right).
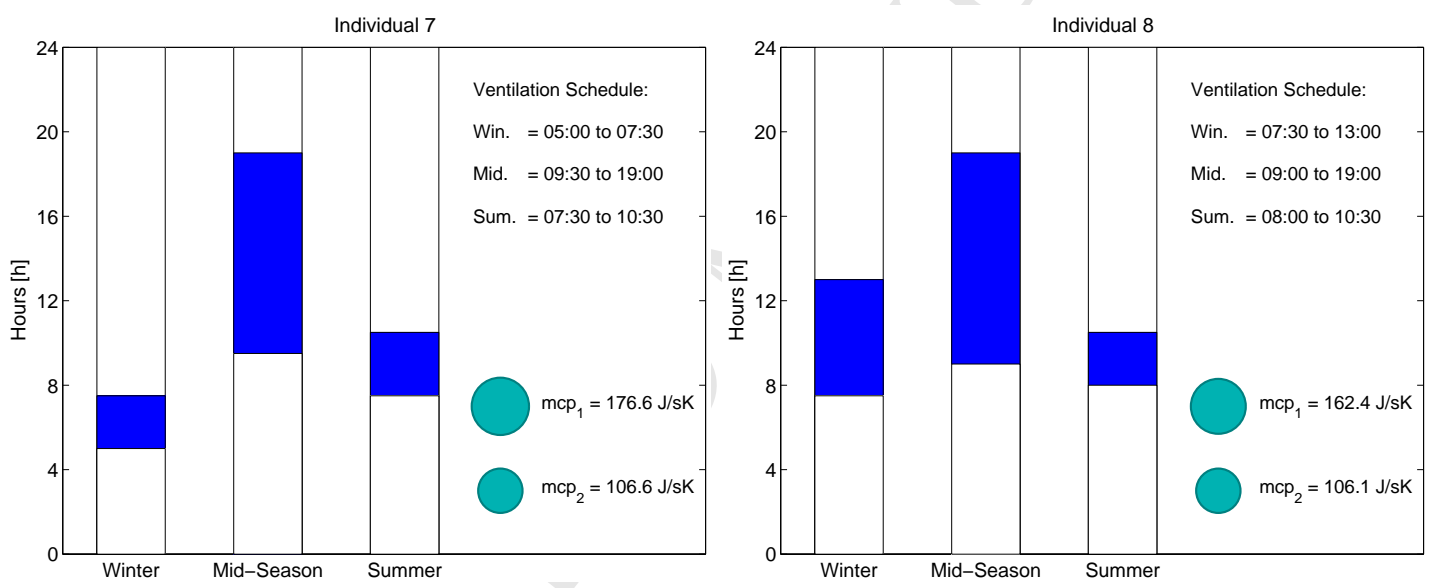

Figure 12: Graphical representation of the schedule of Individuals 7 (on the left) and 8 (on the right).

periods in winter, this is due to the reduction in solidification phase time intervals i.e. more solar radiation transmission into inside zone. While in summer season, in order to reduce thermal loads, the ventilation is needed to keep PCM under its melting/solidification phase. On the other hand, if the ITV is the main target of the optimization by obtaining the minimum difference between the design inside and operative temperature, as mentioned in Equation 33 . the ventilation strategies are reversed. In summer season, air cavities were not ventilated in order to reduce the flattering influence caused by high specific heat capacities values of PCM under its melting/solidification phase. While, during winter season, the ventilation of the cavities allowed the PCM to be under its solid states; accordingly the inside temperatures were 
more closer to the design profile clarified in Table 3 , allowing to obtain the minimum differences all over the heating season. Take into consideration that Figures from 9 to 12 represent an equidistant set among the best solutions of the optimization. However, to better illustrate how the PCM and ventilation timing are affecting temperature profiles, transient behaviour of temperature profiles for two days, i.e. one in summer season (Figure 13a) and the the other in winter season (Figure 13 b), were shown. In summer season and during weekends, the temperature profile of case Ind08 is much closer to the design profile compared to Ind01 during idle hours of the day. During the working hours, the differences between the two individuals profiles have not exceeded $0.5^{\circ} \mathrm{C}$ in respect to design temperature profile. In winter season, also Ind08 was closer than Ind01 in respect to design temperature profile along the day hours.
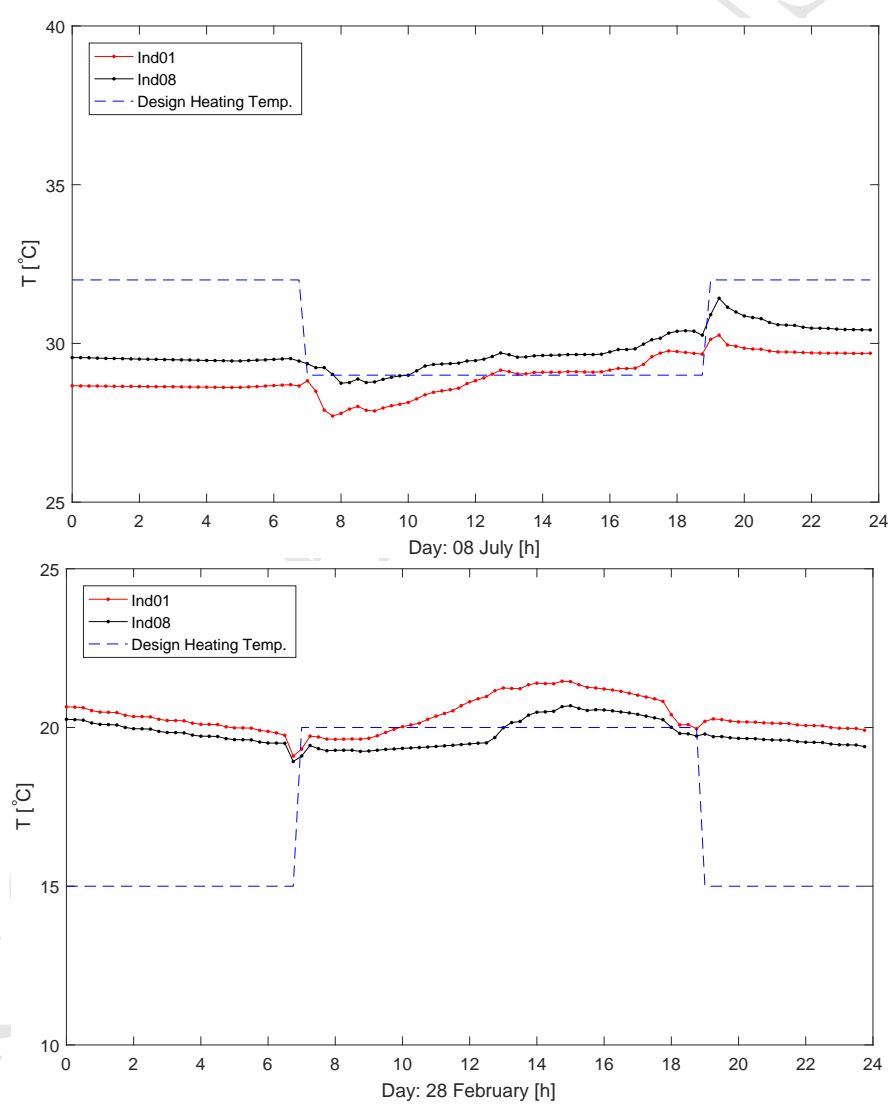

Figure 13: Indoor temperature profiles for different individuals: (a) Summer season, (b) Winter season. 


\subsubsection{PV-PCM Integration Air Thermal Analysis}

365

The eight individuals analysed from Figures 9 to 12 are reflecting the thermal performances of the optimization different solutions. Considering Ind01, during the winter season both cavities $c 1$ and $c 2$ were almost not ventilated. It was enough to depend on the PCM latent heat storage capability. However, the pattern has changed during both the summer and mid seasons. In the mid-season, the cavity ventilation started in 9:30 am and lasted for 8 hours while in the summer season, the ventilation started in 7:30 am and lasted till 17:30 pm. This ventilation schedule has enforced the PCM charging/discharging process efficiently to confront the external and internal loads, in which the PCM works under its highest values of specific heat capacity. With almost the same ventilation schedule in Ind02, the first fitness function i.e. thermal loads has not improved much. On the other hand, by reducing the summer ventilation time period, thermal loads started to increase more. The ventilation flow rates as a whole were considered not to exceed $16 \mathrm{l} / \mathrm{s}$ per façade meter.

The influence of ventilating cavity $c 1$ is higher on the required thermal loads in comparing to cavity c2. The ventilation flow rate of cavity c2 $^{2}$ is almost constant and equal to $4.5 \mathrm{l} / \mathrm{s}$ per façade meter in all seasons while in cavity $c 1$ it ranged between 6 to $8 \mathrm{l} / \mathrm{s}$ per façade meter. This indicates that higher flow rates implemented to cool the PV surface is improving the overall energy balance of the inner zone. On the other hand, PCM requires lesser mass flow rates in respect to its variable physical states and thermal inertia.

The hourly energy profiles for three individuals (Ind01, Ind05 and Ind08) in summer, winter and mid seasons were compared to highlight the performance between different scenarios estimated by the optimization algorithm. During summer season (Figure 14 a) the required cooling load in Ind01 is in between the range of 2 and $4 k W h$ till almost $18 \mathrm{~h}$ and it increases to $5 \mathrm{kWh}$, this peak load meets the ventilation turning off at cavity 2 (see Figure 9a). The same pattern occurred in the other cases; however the thermal requirements rise at $15.00 \mathrm{~h}$ in Ind03 and at $11.00 \mathrm{~h}$ in Ind08; which again confirming the importance of the cavity ventilation schedule. In winter season (Figure 14p) the hourly energy profiles forInd01 and Ind05 are very close. The daily heating energy requirements were recorded as $35 k W h$ and $35.5 k W h$ for both individuals respectively. The trends reflect the similar patterns in ventilation schedule and mass flow rates. On the other hand, Ind08 with the highest ventilation period had the highest heating loads requirements equalled to $43.2 \mathrm{kWh}$ per day. Finally, during the mid season the ventilation schedule and mass flow rates are still the prominent parameters of thermal performance. As 
illustrated in Figure 14k, the minimum daily heating loads of $9 k W h$ were recorded to Ind01, followed by similar performances of hourly energy profiles for Ind05 and Ind08 with a daily consumption of $14 k W h$ and $15 k W h$ per day respectively.
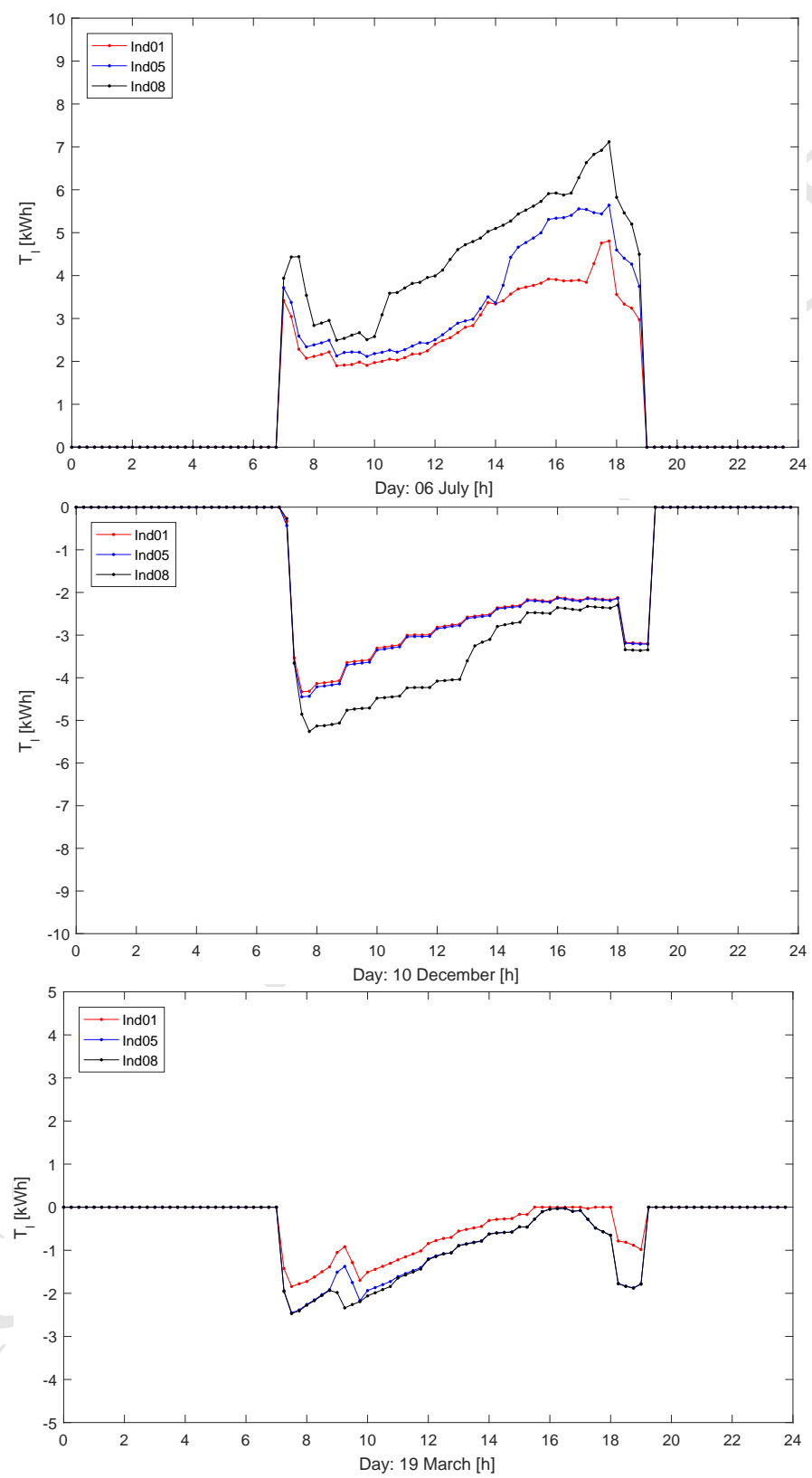

Figure 14: Comparison of daily thermal energy profiles of different solutions (Ind01, Ind05 and Ind08) for days a) 19th March, b) 06th July and c) 10th December. 


\section{Conclusions}

Future works shall upgrade the 1D PV-PCM model to 2D in order to include the stratification influence that might occurs in the higher-altitude façades. Furthermore, PV electrical energy improvements due to PCM integration shall be evaluated. More important, the upcoming 
optimization should focus on the economical aspects to expand the results on urban scale deployment. In fact, the cost of energy definitely represents a main factor and a third contrasting objective to be taken into account during the decision process regarding the PV-PCM module implementation. 


\section{Nomenclature}

\begin{tabular}{|c|c|c|}
\hline$a$ & Solar absorption coefficient & - \\
\hline$c_{l}$ & PCM Liquid specific heat capacity & $J / k g K$ \\
\hline$c_{s}$ & PCM Solid specific heat capacity & $J / k g K$ \\
\hline$C^{A}$ & Heat Capacity & $J / k g K$ \\
\hline$h$ & Convection heat transfer coefficient & $W / m^{2} K$ \\
\hline$h_{c}$ & Air cavity convection heat transfer coefficient & $W / m^{2} K$ \\
\hline$H$ & Enthalpy & $\mathrm{J} / \mathrm{kg}$ \\
\hline$H_{P}$ & Enthalpy node value & $J / k g$ \\
\hline$H_{p}^{o}$ & Enthalpy node value in previou & $J / k g$ \\
\hline$f_{h}$ & Floor height & $m$ \\
\hline$f_{Q}$ & Thermal load fitness & - \\
\hline$f_{\Delta T}$ & Operating temperature fitness & - \\
\hline$i$ & Iteration number & - \\
\hline$I_{t r}$ & Transmitted solar radiation & $k W h$ \\
\hline$L$ & Latent heat of fusion & $J / k g K$ \\
\hline$\dot{m}$ & Mass flow rate & $\mathrm{kg} / \mathrm{s}$ \\
\hline$n$ & Maximum iteration number & - \\
\hline$N_{u}$ & Nusselt Number & - \\
\hline$Q_{t h}$ & Thermal load & $k W h$ \\
\hline$Q_{t h, b a s}$ & Thermal load of baseline individual & $k W h$ \\
\hline$P_{r}$ & Prandtl Number & - \\
\hline$R_{e}$ & Reynolds Number & - \\
\hline$t$ & Time & $\mathrm{s}$ \\
\hline$T$ & Temperature & $K$ \\
\hline$T_{a} c$ & Temperature of air cavity & $K$ \\
\hline$T_{d e}$ & Design temperature & $K$ \\
\hline$T_{m}$ & Melting peak temperature & $K$ \\
\hline$T_{n b}$ & Adjacent nodes Temperature & $K$ \\
\hline$T_{o p}$ & Operating temperature & $K$ \\
\hline$T_{P}$ & PCM node Temperature & $K$ \\
\hline
\end{tabular}




\begin{tabular}{|c|c|c|c|}
\hline$k$ & \multicolumn{2}{|c|}{ Thermal conductivity coefficient } & $W / m K$ \\
\hline$R$ & \multicolumn{2}{|c|}{ Thermal Resistance } & $m^{2} K / W$ \\
\hline$v$ & \multicolumn{2}{|c|}{ Air velocity } & $\mathrm{m} / \mathrm{s}$ \\
\hline$X$ & \multicolumn{2}{|c|}{ Vector of Genes } & - \\
\hline$\Delta T_{\text {bas }}$ & \multicolumn{2}{|c|}{ Temperature difference in baseline individual } & $K$ \\
\hline$\varepsilon$ & \multicolumn{2}{|c|}{ Arbitrary small temperature value } & $K$ \\
\hline$\rho$ & \multicolumn{2}{|c|}{ Mass density } & $\mathrm{kg} / \mathrm{m}^{3}$ \\
\hline$\tau$ & \multicolumn{2}{|c|}{ Time step } & \\
\hline & \multirow{2}{*}{$\begin{array}{c}H V A C \\
I T V\end{array}$} & \multicolumn{2}{|l|}{ Heating Ventilation and Air Conditioning } \\
\hline & & Indoor Temperature Variation & \\
\hline & $P C M$ & Phase Change Material & \\
\hline & $P V$ & Photo Voltaices & \\
\hline & $n Z E B$ & nearly Zero Energy Building & \\
\hline
\end{tabular}




\section{References}

[1] A. El-Sawi, F. Haghighat, and H. Akbari, "Assessing long-term performance of centralized thermal energy storage system," Applied Thermal Engineering, vol. 62, no. 2, pp. 313-321, 2014.

[2] M. D. Grassi, A. Carbonari, and G. Palomba, "A statistical approach for the evaluation of the thermal behavior of dry assembled pcm containing walls," Building and Environment, vol. 41, no. 4, pp. $448-485,2006$.

[3] G. Evola, L. Marletta, and F. Sicurella, "A methodology for investigating the effectiveness of pcm wallboards for summer thermal comfort in buildings," Building and Environment, vol. 59, pp. $517-527,2013$.

[4] L. Li, H. Yu, and R. Liu, "Research on composite-phase change materials (pcms)-bricks in the west wall of room-scale cubicle: Mid-season and summer day cases," Building and Environment, vol. 123, pp. 494 - 503, 2017.

[5] C.-M. Lai and S. Hokoi, "Solar façades: A review," Building and Environment, vol. 91, pp. 152-165, 2015.

[6] B. Nghana and F. Tariku, "Phase change material's (pcm) impacts on the energy performance and thermal comfort of buildings in a mild climate," Building and Environment, vol. 99, pp. 221 - 238, 2016.

[7] X. Jin, S. Zhang, X. Xu, and X. Zhang, "Effects of pcm state on its phase change performance and the thermal performance of building walls," Building and Environment, vol. 81, pp. 334 - 339, 2014.

[8] P. C. Tabares-Velasco, C. Christensen, and M. Bianchi, "Verification and validation of energyplus phase change material model for opaque wall assemblies," Building and Environment, vol. 54, pp. 186 - 196, 2012.

[9] A. Machniewicz, D. Knera, and D. Heim, "Effect of transition temperature on efficiency of pv/pcm panels," Energy Procedia, vol. 78, pp. 1684-1689, 2015. 
[10] J. Urbanetz, C. D. Zomer, and R. Rüther, "Compromises between form and function in grid-connected, building-integrated photovoltaics (bipv) at low-latitude sites," Building and Environment, vol. 46, no. 10, pp. 2107 - 2113, 2011.

[11] W. Tian, Y. Wang, Y. Xie, D. Wu, L. Zhu, and J. Ren, "Effect of building integrated photovoltaics on microclimate of urban canopy layer," Building and Environment, vol. 42, no. 5, pp. $1891-1901,2007$.

[12] S. Yoon, S. Tak, J. Kim, Y. Jun, K. Kang, and J. Park, "Application of transparent dye-sensitized solar cells to building integrated photovoltaic systems," Building and Environment, vol. 46, no. 10, pp. 1899 - 1904, 2011.

[13] T. Ma, H. Yang, Y. Zhang, L. Lu, and X. Wang, "Using phase change materials in photovoltaic systems for thermal regulation and electrical efficiency improvement: A review and outlook," Renewable and Sustainable Energy Reviews, vol. 43, pp. 1273-1284, 2015.

[14] K. Pielichowska and K. Pielichowski, "Phase change materials for thermal energy storage," Progress in materials science, vol. 65, pp. 67-123, 2014.

[15] V. L. Brano, G. Ciulla, A. Piacentino, and F. Cardona, "Finite difference thermal model of a latent heat storage system coupled with a photovoltaic device: Description and experimental validation," Renewable Energy, vol. 68, pp. 181-193, 2014.

[16] H. Elarga, F. Goia, and E. Benini, "Pv-pcm integration in glazed buildings. numerical study through matlab/trnsys linked model." in Building Simulation Application conference, Bolzano Italy, vol. 3. https://www.researchgate.net/publication/313572061, 2017, p. 8.

[17] H. Elarga, S. Fantucci, V. Serra, R. Zecchin, and E. Benini, "Experimental and numerical analyses on thermal performance of different typologies of pcms integrated in the roof space," Energy and Buildings, 2017.

[18] Y. Lu, S. Wang, and K. Shan, "Design optimization and optimal control of grid-connected and standalone nearly/net zero energy buildings," Applied Energy, vol. 155, pp. 463-477, 2015.

[19] A. d. Gracia Cuesta, R. Barzin, C. Fernàndez Camon, M. M. Farid, and L. F. Cabeza, "Control strategies comparison of a ventilated facade with pcm-energy savings, cost reduction and co2 mitigation," Energy and Buildings, 2016, vol. 130, p. 821-828, 2016. 
[20] M. Hamdy, A. Hasan, and K. Siren, "Applying a multi-objective optimization approach for design of low-emission cost-effective dwellings," Building and environment, vol. 46, no. 1, pp. 109-123, 2011.

[21] H. Analysis and T. Kalamees, "Ida ice: the simulation tool for."

[22] E. Asadi, M. G. da Silva, C. H. Antunes, and L. Dias, "A multi-objective optimization model for building retrofit strategies using trnsys simulations, genopt and matlab," Building and Environment, vol. 56, pp. 370-378, 2012.

[23] F. Ascione, N. Bianco, C. De Stasio, G. M. Mauro, and G. P. Vanoli, "Simulationbased model predictive control by the multi-objective optimization of building energy performance and thermal comfort," Energy and Buildings, vol. 111, pp. 131-144, 2016.

[24] S. Carlucci, G. Cattarin, F. Causone, and L. Pagliano, "Multi-objective optimization of a nearly zero-energy building based on thermal and visual discomfort minimization using a non-dominated sorting genetic algorithm (nsga-ii)," Energy and Buildings, vol. 104, pp. 378-394, 2015.

[25] S. Bambrook, A. Sproul, and D. Jacob, "Design optimisation for a low energy home in sydney," Energy and Buildings, vol. 43, no. 7, pp. 1702-1711, 2011.

[26] L. Wang, J. Gwilliam, and P. Jones, "Case study of zero energy house design in uk," Energy and buildings, vol. 41, no. 11, pp. 1215-1222, 2009.

[27] S. Bucking, R. Zmeureanu, and A. Athienitis, "A methodology for identifying the influence of design variations on building energy performance," Journal of Building Performance Simulation, vol. 7, no. 6, pp. 411-426, 2014.

[28] Y. Sun, "Sensitivity analysis of macro-parameters in the system design of net zero energy building," Energy and Buildings, vol. 86, pp. 464-477, 2015.

[29] H. Elarga, F. Goia, A. Zarrella, A. Dal Monte, and E. Benini, "Thermal and electrical performance of an integrated pv-pcm system in double skin façades: A numerical study," Solar Energy, vol. 136, pp. 112-124, 2016.

[30] A. Dal Monte, M. R. Castelli, and E. Benini, "Multi-objective structural optimization of a hawt composite blade," Composite Structures, vol. 106, pp. 362-373, 2013. 
[31] A. Dal Monte, S. De Betta, M. R. Castelli, and E. Benini, "Proposal for a coupled aerodynamic-structural wind turbine blade optimization," Composite Structures, vol. 159, pp. 144-156, 2017.

[32] MATLAB, version R2013b. Natick, Massachusetts: The MathWorks Inc., 2013.

[33] H. C. Hottel and W. McAdams, "Heat transmission," 1954.

[34] I. Beausoleil-Morrison, The adaptive coupling of heat and air flow modelling within dynamic whole-building simulation. University of Strathclyde UK, 2000.

[35] Y. Çengel, "Heat and mass transfer, a practical approach," New York, 2007.

[36] S. Patankar, Numerical heat transfer and fluid flow. CRC press, 1980.

[37] H. Elarga, M. De Carli, and A. Zarrella, "A simplified mathematical model for transient simulation of thermal performance and energy assessment for active facades," Energy and Buildings, vol. 104, pp. 97-107, 2015.

[38] M. De Carli, H. Elarga, A. Zarrella, and M. Tonon, "Evaluation of energy recovery of multiple skin facades: The approach of digithon," Energy and Buildings, vol. 85, pp. 337$345,2014$.

[39] H. Elarga, A. Zarrella, and M. De Carli, "Dynamic energy evaluation and glazing layers optimization of facade building with innovative integration of pv modules," Energy and Buildings, vol. 111, pp. 468-478, 2016.

[40] F. Goia, M. Perino, and M. Haase, "A numerical model to evaluate the thermal behaviour of pcm glazing system configurations," Energy and Buildings, vol. 54, pp. 141-153, 2012.

[41] V. Voller, "An overview of numerical methods for solving phase change problems," Advances in numerical heat transfer, vol. 1, no. 9, pp. 341-380, 1997.

[42] S. Klien, W. Beckman, J. Mitchell, J. Duffie, N. Duffie, T. Freeman, J. Mitchell, J. Braun, B. Evans, J. Kummer et al., "Trnsys 16-a transient system simulation program, user manual," Solar Energy Laboratory. Madison, WI: University of Wisconsin-Madison, 2004.

[43] "Rubitherm," https://www.rubitherm.eu/en/, accessed: 2017-06-12. 
545 [44] J. Parra, A. Guardo, E. Egusquiza, and P. Alavedra, "Thermal performance of ventilated double skin façades with venetian blinds," Energies, vol. 8, no. 6, pp. 4882-4898, 2015.

[45] M. Kragh, "Monitoring of advanced facades and environmental systems," whole-life performance of facades University of Bath, CWCT, 2001. 
- Develop 1-D model describing thermal and energy performance of PV-PCM module

- Clarify how to couple TRNSYS software to the 1-D model

- Develop a genetic optimization algorithm to investigate parameters affect thermal performance of PV-PCM glazed modules 